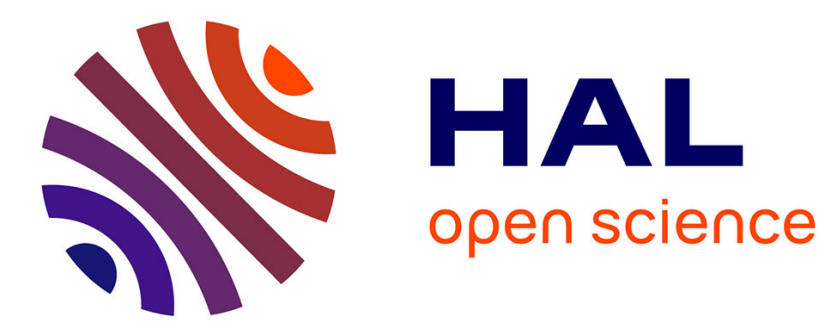

\title{
Modeling Slab Temperature: A Reevaluation of the Thermal Parameter
}

B. Maunder, J. Hunen, P. Bouilhol, V. Magni

\section{To cite this version:}

B. Maunder, J. Hunen, P. Bouilhol, V. Magni. Modeling Slab Temperature: A Reevaluation of the Thermal Parameter. Geochemistry, Geophysics, Geosystems, 2019, 20 (2), pp.673-687. 10.1029/2018GC007641 . hal-02934713

\section{HAL Id: hal-02934713 \\ https://hal.science/hal-02934713}

Submitted on 7 Jan 2022

HAL is a multi-disciplinary open access archive for the deposit and dissemination of scientific research documents, whether they are published or not. The documents may come from teaching and research institutions in France or abroad, or from public or private research centers.
L'archive ouverte pluridisciplinaire HAL, est destinée au dépôt et à la diffusion de documents scientifiques de niveau recherche, publiés ou non, émanant des établissements d'enseignement et de recherche français ou étrangers, des laboratoires publics ou privés. 


\section{Geochemistry, Geophysics, Geosystems}

\author{
RESEARCH ARTICLE \\ 10.1029/2018GC007641 \\ Key Points: \\ - New slab temperature indicator is \\ more accurate/detailed than the \\ thermal parameter for depths \\ $<120 \mathrm{~km}$ \\ - Slab mantle temperature is \\ controlled by slab age; subarc slab \\ crust temperature is controlled \\ primarily by subduction speed \\ - A variable plate decoupling depth \\ has a larger effect on slab crust \\ temperature, in the subarc region, \\ than other slab parameters
}

Supporting Information:

- Supporting Information S1

Correspondence to:

B. Maunder,

b.maunder@ic.ac.uk

Citation:

Maunder, B., van Hunen, J., Bouilhol, P. \& Magni, V. (2019). Modeling slab temperature: A reevaluation of the thermal parameter. Geochemistry, Geophysics, Geosystems, 20, 673-687. https://doi.org/10.1029/2018GC007641

Received 1 MAY 2018

Accepted 29 DEC 2018

Accepted article online 5 JAN 2019

Published online 1 FEB 2019

(C)2019. American Geophysical Union. All Rights Reserved.

\section{Modeling Slab Temperature: A Reevaluation of the Thermal Parameter}

\author{
B. Maunder ${ }^{1,2}$ iD, J. van Hunen ${ }^{1}$ iD, P. Bouilhol ${ }^{3}$ iD, and V. Magni ${ }^{4}$ \\ ${ }^{1}$ Department of Earth Sciences, Durham University, Durham, UK, ${ }^{2}$ Now at Department of Earth Science and Engineering, \\ Imperial College London Royal School of Mines, London, UK, ${ }^{3} \mathrm{CRPG}$, University of Lorraine, Nancy, France, ${ }^{4}$ Centre for \\ Earth Evolution and Dynamics (CEED), Department of Geosciences, University of Oslo, Oslo, Norway
}

\begin{abstract}
We reevaluate the effects of slab age, speed, and dip on slab temperature with numerical models. The thermal parameter $\Phi=t v \sin \theta$, where $t$ is age, $v$ is speed, and $\theta$ is angle, is traditionally used as an indicator of slab temperature. However, we find that an empirically derived quantity, in which slab temperature $T \propto \log \left(t^{-a} v^{-b}\right)$, is more accurate at depths $<120 \mathrm{~km}$, with the constants $a$ and $b$ depending on position within the slab. Shallower than the decoupling depth $(\sim 70-80 \mathrm{~km}), a \sim 1$ and $b \sim 0$, that is, temperature is dependent on slab age alone. This has important implications for the early devolatilization of slabs in the hottest (youngest) cases and for shallow slab seismicity. At subarc depths ( 100 km), within the slab mantle, $a \sim 1$ and $b \sim 0$ again. However, for the slab crust, now $a \sim 0.5$ and $b \sim 1$, that is, speed has the dominant effect. This is important when considering the generation of arc magmatism, and in particular, slab melting and the generation of slab-derived melange diapirs. Moving deeper into the Earth, the original thermal parameter performs well as a temperature indicator, initially in the core of the slab (the region of interest for deep water cycling). Finally, varying the decoupling depth between 40 and $100 \mathrm{~km}$ has a dominant effect on slab temperatures down to $140-\mathrm{km}$ depth, but only within the slab crust. Slab mantle temperature remains primarily dependent on age.
\end{abstract}

\section{Introduction}

The thermal structure of subducting slabs has a first-order control on many aspects of subduction zones. Crucially, slab temperature controls slab devolatilization, affecting the chemistry of the slab component found in arc magma, as well as the amount of volatiles recycled back to the deep mantle (Magni et al., 2014; van Keken et al., 2011). Such control on the cycling of elements back to the surface via the associated arc magmatism is central to our understanding of the formation of evolved crustal material that ultimately forms the continental crust. Indeed, key elements that define arc geochemical signatures are also found in the continental crust (Rudnick, 1995) and are strongly dependent on slab temperature (Kessel et al., 2005). Similarly, slab temperature ultimately controls the rheology of the subducting material (Maunder et al., 2016), which may become buoyant with respect to the mantle and forms diapirs (Gerya \& Yuen, 2003; Marschall \& Schumacher, 2012) that will have a profound effect on the chemistry of arc magmatism (Behn et al., 2011) and lower continental crust (Hacker et al., 2011).

From a geophysical perspective, subduction is driven by slab pull (Forsyth \& Uyeda, 1975) primarily due to the negative thermal buoyancy of slabs, and therefore, the thermal state of slabs should also have a large effect on the balance of forces within the subduction system and the stress state of the slab (England \& Wortel, 1980). As such, slab temperature also influences seismicity within the slab (Gorbatov \& Kostoglodov, 1997; Helffrich \& Brodholt, 1991); the motion of the trench and therefore stress state of the overriding plate (Lallemand et al., 2008); and the interaction of the slab with the 660-km transition zone (Agrusta et al., 2017).

Plank et al. (2009) point out that there are two primary methods by which the temperature of a presently subducting slab can be determined: (1) by analysis of the arc magmatism above them and (2) by forward geodynamic modeling using known physical parameters. We focus here on the latter. Much work has already been done in trying to characterize the thermal profile of slabs and in particular how this depends on other physical parameters such as the slab age (referred to from now on as age), trench normal convergence rate (referred to from now on as speed), and slab dip angle (referred to from now on as angle). The subduction "thermal parameter", or $\Phi=t v \sin \theta$, where $t$ is age, $v$ is speed, and $\theta$ is angle, has commonly been used as a first-order measure of the internal temperature of slabs (Kirby et al., 1996). Slab top 
temperature has been predicted to be related to this thermal parameter and depth $z$ when shallower than the base of the overriding lithosphere: $T=1 / \sqrt{1+\Phi / z}$ (Molnar \& England, 1995; Syracuse et al., 2010). At greater depths, McKenzie (1969) theorized that, due to the heating effect of the overlying mantle wedge, a more accurate expression for internal slab temperature at these depths is given by $T=1-(2 / \pi)$ $\exp \left(-\left(\pi^{2} / 5.38\right) z / \Phi\right)$. Both these expressions use the thermal parameter and therefore equally weight the effect of age, speed, and angle on the thermal profile.

However, since then, more detailed studies have been undertaken, including the use of numerical simulations. Van Keken et al. (2011) use numerical models to demonstrate that there is an existing but fairly weak correlation between slab temperatures at subarc depths and $\ln (\phi)$. Syracuse et al. (2010) produce numerical subduction models for 52 modern arc segments to determine their thermal profiles. They find that the proposed relationships work reasonably well for slab temperatures at shallow depths and also at greater depths but fail to give strong correlations in the crucial subarc region. Magni et al. (2014) show that slab velocity has the strongest control on the thermal structure of slabs at subarc slab depths (60-170 km) and that its effect is not straightforward: Faster slabs have colder interiors but hotter slab surfaces. Similar numerical studies have also investigated the effect the thermal state of slabs has on the fate of subducted volatiles (Peacock, 1990), and the feedback the behavior of volatiles has on the thermal state of slabs (Arcay et al., 2007). Another factor that is likely to play a crucial role is the thickness of the overriding plate (or decoupling depth; Currie et al., 2004), which is not encompassed in the current definition of the thermal parameter.

It has been suggested that certain geochemical signatures do show some correlation with the thermal parameter (Cooper et al., 2012; Ruscitto et al., 2012). However, the correlation is not strong and in fact weaker than correlation with other parameters, such as the overriding Moho depth (Turner \& Langmuir, 2015). This could mean that the thermal state of the slab plays a smaller role in determining the geochemical characteristics of arc magmas or that, for this purpose, the thermal parameter is not performing sufficiently well as an indicator for temperature. In this study, we readdress the use of the thermal parameter as an indicator of slab temperature at different points within the interior of subducting slabs at subarc depths. In accordance with the previously mentioned studies, we find that the original definition of the thermal parameter performs well for internal slab temperatures deeper in the mantle (approximately more than $150 \mathrm{~km}$ ). However, we find that age has a dominant control on internal slab temperatures shallower than this depth and slab top temperatures shallower than the decoupling depth (at $70 \mathrm{~km}$ ) and that speed dominates for slab top temperatures deeper than the decoupling depth (arguably the most important region when considering fluid release and arc magma genesis). We also investigate the effect of a change in the decoupling depth. We find that, when varied, it has a stronger effect on slab temperature than any of the slab parameters, in a region that extends from the shallowest decoupling depth $(40 \mathrm{~km})$ to $40 \mathrm{~km}$ deeper than the deepest decoupling depth $(140 \mathrm{~km})$. However, this is only within the slab crust: In the slab mantle, slab temperature is still primarily age controlled.

\section{Methods}

\subsection{Model Setup}

For this study, we adapted a model we developed for a previous study of subduction, and the reader is referred to Maunder et al. (2016) for further details of the model setup. This is a 2-D model, developed using a Cartesian version of the finite element code Citcom (Moresi \& Gurnis, 1996; Zhong et al., 2000), which solves the coupled equations for the conservation of mass, momentum, and temperature while assuming incompressibility and using the Boussinesq approximation. Shear heating is not included (see section 4.2). Composition is tracked by tracers that are conservatively advected (i.e., such that the divergence of the velocity field, interpolated from the element nodes, is always 0) with the flow field (Wang et al., 2015).

The model is $700 \mathrm{~km}$ wide and $200 \mathrm{~km}$ deep and consists of $512 \times 256$ finite elements with horizontal mesh refinement such that an element in the region of interest is $800 \times 800 \mathrm{~m}$. As subduction is driven by a negatively buoyant slab, which extends to beyond 200-km depth in reality (Forsyth \& Uyeda, 1975), we add an additional slab pull force to the downgoing slab at the bottom boundary (Maunder et al., 2016). This allows for subduction speed to be set by us and maintained throughout the model run. Slab dip is set by applying a variable shear between the top and bottom boundaries (achieved via a fixed velocity bottom boundary 


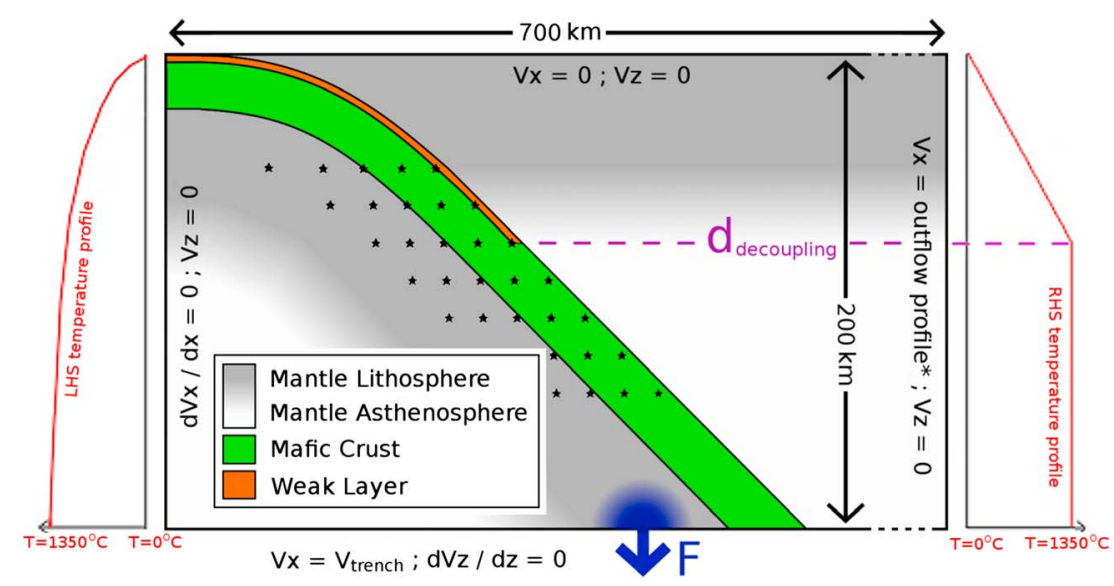

Figure 1. Initial positioning of all materials. The left-hand side (LHS) boundary is open and allows for horizontal inflow of material with a half-space cooling temperature profile characterized by the slab age, $t$. The right-hand side (RHS) boundary has a fixed, horizontal outflow profile* with a thermal profile of an older plate, with $0{ }^{\circ} \mathrm{C}$ surface temperature, $1350^{\circ} \mathrm{C}$ mantle temperature when deeper than the decoupling depth, and linearly interpolated in between. A vertical body force is applied to an area within the subducting lithosphere at the base of the model. The magnitude of this force is continually adjusted to maintain a constant slab velocity and the area moved to remain a fixed distance from the slab to the Moho. The top boundary is closed and no slip with a fixed surface temperature. The bottom boundary is open (stress-free vertically) but with the horizontal component of the velocity set to $v_{\text {trench }}=v \cos (\theta)$ to ensure that the plate subducts at a certain angle, $\theta$. The black stars indicate the points within the slab where the temperature is measured. For clarity, only every other sample point has been marked. The horizontal axis has been compressed where the boundary is dashed. The right-hand side boundary is significantly further from the slab, such that this boundary does not affect mantle flow in the vicinity of the slab. Asterisk $\left(^{*}\right)$ indicates that outflow profile is zero flux at points shallower than the decoupling depth and linearly increases with depth to $v_{\text {trench }}$ by the base of the model.

condition, or $v_{\text {trench }}$, which represents relative motion with respect the mantle below the model domain). It has been suggested that, in order to achieve low-angle subduction, such a shear does need to exist (van Hunen et al., 2004), although we recognize that there are other factors that may also play a role and this is a simplification. The left-hand side thermal boundary condition is that of a half space that has been cooled over a certain time: the slab age. We run the model through an initialization stage to ensure that the slab is in approximate thermal and mechanical equilibrium. Boundary and initial conditions are summarized in Figure 1. In this study, we refer to the slab dip as the angle at which the slab leaves the model through the bottom boundary, which directly controls the stable geometry of the entire slab (see supporting information).

\subsection{Rheology}

Material deforms viscously by diffusion and dislocation creep mechanisms (with no pressure dependence), operating in parallel:

$$
\begin{gathered}
\eta=\frac{1}{\frac{1}{\eta_{\text {disl }}}+\frac{1}{\eta_{\text {diff }}}}, \\
\eta_{\mathrm{i}}=A_{\mathrm{i}}^{\frac{1}{n_{\mathrm{i}}}} \cdot \frac{1-n_{\mathrm{i}}}{\dot{\varepsilon}^{n_{\mathrm{i}}}} \exp \left(\frac{E_{\mathrm{i}}}{n_{\mathrm{i}} R T}\right)
\end{gathered}
$$

The definitions of the symbols used are given in Table 1, and the subscript, $i$, either refers to diffusion creep ("diff") or dislocation creep ("disl"). Two different compositions are included in this model: (dry) mantle peridotite, and (partially hydrated) mafic oceanic crust (gabbro). The different compositions have different values of $A, E$, and $n$, which are informed by a detailed literature study (see the supporting information of Maunder et al., 2016).

A weak zone, which terminates at a fixed decoupling depth (70 km unless stated otherwise), decouples the two plates (Figure 1). Its geometry is not fixed and is allowed to move with the top of the slab until the slab 
Table 1

Symbols, Units, and Values of Properties and Model-Defining Constants

\begin{tabular}{|c|c|c|c|}
\hline Symbol & Description & Units & (Default) value \\
\hline$t$ & Age (slab age) & Myr & - \\
\hline$v$ & Speed (trench normal convergence rate) & $\mathrm{m} / \mathrm{s}$ & - \\
\hline$\theta$ & Angle (slab dip angle) & $\circ$ & - \\
\hline$T$ & Temperature & ${ }^{\circ} \mathrm{C}$ & - \\
\hline$z$ & Depth & $\mathrm{m}$ & - \\
\hline$\dot{\varepsilon}$ & Strain rate & $s^{-1}$ & - \\
\hline$A_{\text {diff }}$ mantle & Rheological prefactor for mantle diffusion creep & $\mathrm{Pa}^{-n} \cdot \mathrm{S}^{-1}$ & $4.61 \times 10^{9}$ \\
\hline$A_{\text {diff }}$ crust & Rheological prefactor for crustal diffusion creep & $\mathrm{Pa}^{-n} \cdot \mathrm{s}^{-1}$ & $4.61 \times 10^{9}$ \\
\hline$E_{\text {diff }}$ mantle & Activation energy for mantle diffusion creep & $\mathrm{J} / \mathrm{mol}$ & $3.79 \times 10^{5}$ \\
\hline$E_{\text {diff }}$ crust & Activation energy for crustal diffusion creep & $\mathrm{J} / \mathrm{mol}$ & $3.79 \times 10^{5}$ \\
\hline$n_{\text {diff }}$ mantle & Stress exponent for mantle diffusion creep & - & 1 \\
\hline$n_{\text {diff }}$ crust & Stress exponent for crustal diffusion creep & - & 1 \\
\hline$A_{\text {disl }}$ mantle & Rheological prefactor for mantle dislocation creep & $\mathrm{Pa}^{-n} \cdot \mathrm{s}^{-1}$ & $5.92 \times 10^{15}$ \\
\hline$A_{\text {disl }}$ crust & Rheological prefactor for crustal dislocation creep & $\mathrm{Pa}^{-n} \cdot \mathrm{s}^{-1}$ & $7.49 \times 10^{19}$ \\
\hline$E_{\text {disl }}$ mantle & Activation energy for mantle dislocation creep & $\mathrm{J} \mathrm{mol}^{-1}$ & $5.42 \times 10^{5}$ \\
\hline$E_{\text {disl }}$ crust & Activation energy for crustal dislocation creep & $\mathrm{J} / \mathrm{mol}$ & $2.83 \times 10^{5}$ \\
\hline$n_{\text {disl }}$ mantle & Stress exponent for mantle dislocation creep & - & 3.48 \\
\hline$n_{\text {disl }}$ crust & Stress exponent for crustal dislocation creep & - & 3.08 \\
\hline$R$ & Gas constant & $\mathrm{J} \cdot \mathrm{K}^{-1} \cdot \mathrm{mol}^{-1}$ & 8.31 \\
\hline$T_{0}$ & Surface temperature & ${ }^{\circ} \mathrm{C}$ & 0 \\
\hline$\Delta T$ & Temperature of the mantle relative to $T_{0}$ & ${ }^{\circ} \mathrm{C}$ & 1350 \\
\hline$\rho$ & Density of the mantle & $\mathrm{kg} / \mathrm{m}^{3}$ & 3300 \\
\hline$\rho_{\text {crust }}$ & Density of oceanic crust above $d_{\text {eclogite }}$ & $\mathrm{kg} / \mathrm{m}^{3}$ & 3100 \\
\hline Peclogite & Density of oceanic crust below $d_{\text {eclogite }}$ & $\mathrm{kg} / \mathrm{m}^{3}$ & 3400 \\
\hline$d_{\text {crust }}$ & Incoming crustal thickness & $\mathrm{km}$ & 7.5 \\
\hline$d_{\text {eclogite }}$ & Depth of the crustal transition from basalt to eclogite & $\mathrm{km}$ & 100 \\
\hline$d_{\text {decoupling }}$ & Decoupling depth: the maximum depth of the weak zone & $\mathrm{km}$ & 70 \\
\hline$\eta_{\text {weak zone }}$ & Viscosity of weak zone & $\mathrm{Pa} \cdot \mathrm{s}$ & $10^{20}$ \\
\hline$\eta_{\max }$ & Maximum viscosity & $\mathrm{Pa} \cdot \mathrm{s}$ & $10^{24}$ \\
\hline$h$ & Model depth & $\mathrm{km}$ & 200 \\
\hline$\kappa$ & Thermal diffusivity & $\mathrm{m}^{2} / \mathrm{s}$ & $8 \times 10^{-7}$ \\
\hline$g$ & Acceleration due to gravity & $\mathrm{m} / \mathrm{s}^{2}$ & 9.8 \\
\hline$\alpha$ & Thermal expansivity & $\mathrm{K}^{-1}$ & $3.5 \times 10^{-5}$ \\
\hline
\end{tabular}

finds its steady state geometry, during the initialization stage (see supporting information). Its viscosity is fixed at $10^{20} \mathrm{~Pa} \cdot \mathrm{s}$ in the center, defined by a thin layer of tracers $(<<1 \mathrm{~km}$ thick) at the top of the slab. Viscosity of material on both the slab side and overriding plate side of this layer logarithmically increases to the background viscosity over a fixed distance: $\sim 5 \mathrm{~km}$ at the top of the model, which reduces to $\sim 2 \mathrm{~km}$ at the decoupling depth to minimize the effect of the weak zone on the mantle wedge dynamics. By using this technique, the weak zone is centered on the top of the slab. Brittle yielding is not included as it is deemed not to play a significant role in our region of interest: the subducting crust and overlying mantle, below the overriding plate. Instead, we impose a maximum viscosity of $10^{24} \mathrm{~Pa} \cdot \mathrm{s}$, which limits the maximum stresses achievable within the rheologically stronger regions of the model.

\subsection{Parametric Study}

To investigate the relative importance of age $(t)$, speed $(v)$, and angle $(\theta)$, we reformulate the thermal parameter into an adjusted thermal parameter (ATP) in a way that allows for the relative importance of $t, v$, and $\theta$ to be modulated:

$$
A T P=t^{a} v^{b} \sin \theta^{c}
$$

We then use a dynamic, two-dimensional, numerical model of subduction to determine the relative weightings $(a, b$, and $c$ ) that optimize ATP as an indicator for temperatures at different points within the slab. We repeat model runs for different, fixed ages, speeds, and angles. The explored ranges for these properties were chosen to be representative of global subduction zones today and are as follows: 3, 6, 9, and 
$12 \mathrm{~cm}$ /year; $20,40,60$, and $80 \mathrm{Myr}$; and $30^{\circ}, 45^{\circ}, 60^{\circ}$, and $75^{\circ}$ for speed, age, and angle, respectively (so that a total of 64 models were run). This is informed by the global subduction database "SubMap" (Heuret \& Lallemand, 2005), which includes physical data for all unperturbed (i.e., far from abnormal subducting plates; see Heuret \& Lallemand, 2005, for the full definition) subduction zone segments ( 200 km wide) worldwide.

During each model calculation, we track the pressure-temperature (PT) paths through a cross section from the $1.5 \mathrm{~km}$ perpendicular from the slab top through the oceanic crust and slab mantle down to $15 \mathrm{~km}$ from the slab top. We do this by recording the PT conditions experienced by tracers at these locations within the slab. This method prevents us from tracking the PT conditions of the top kilometer of the slab reliably due to tracers interacting with the weak zone. The locations within the slab that are ultimately sampled are indicated by black stars in Figure 1. Each model calculation has a definite fixed age, speed, and angle, and using these, we then calculate a range of ATPs for each model, varying $a, b$, and $c$ (see equation (3)) with a resolution of 0.1. A plot is then made of temperature (at the same particular point in the slab for the 64 models) versus $\log _{10}$ (ATP), for each combination of $a, b$, and $c$, and an $r^{2}$ value calculated for the strength of correlation (see Figure 6). The values of $a, b$, and $c$ that maximize $r^{2}$ define the "optimal" ATP. The reason the logarithm of the ATP is used is because it has already been shown by van Keken et al. (2011) that an, albeit noisy, linear correlation exists between slab temperature at different points in the slab and $\log _{10}(\Phi)$. As we take the logarithm of the ATP, only the relative values of $a, b$, and $c$ are of importance as multiplying all three by the same constant serves only to dilate the plot of temperature versus ATP, leaving $r^{2}$ unaffected. This reduces the three-dimensional search space to three surfaces within this space, which we choose to be

$$
\begin{aligned}
& a=1 ; \quad-1<b<1 ; \quad-1<c<1, \\
& b=1 ; \quad-1<c<1 ; \quad-1<a<1, \\
& c=1 ; \quad-1<a<1 ; \quad-1<b<1,
\end{aligned}
$$

which, crucially, includes the point $a=1, b=1$, and $c=1$, for which the ATP reduces to the original definition of the thermal parameter $(\Phi)$.

We repeat this same study, this time keeping angle fixed at $45^{\circ}$ and varying the overriding plate thickness or, rather, decoupling depth (Syracuse et al., 2010; Wada \& Wang, 2009), as this is deemed to have a significant effect on the thermal structure (Currie et al., 2004).

\section{Results}

\subsection{The Effect of Speed, Age, and Angle on Slab Geotherms}

All models within the default (present day) study ran to the point where the slab isotherms no longer change significantly with time, that is, thermal "pseudo-equilibrium" (see Figure 2 for an examples of model snapshots). However, two models reached a point where the solver failed to converge on a solution, during the process of measuring the PT paths, due to high viscosity contrasts (see caption of Figure 3 for more details).

Averaging geotherms in models with a shared property (the same slab velocity/age/angle) allows us to gauge how these properties affect the slab geotherm at different points within the slab. These geotherm comparisons are presented in Figure 3 for the slab top, Moho, and the slab mantle at $12 \mathrm{~km}$ perpendicular from the slab top. Varying age and speed has a larger effect on slab temperature than varying dip angle. The effect of age is reasonably constant with depth and increases considerably with distance from the slab top. The effect of velocity increases with depth, particularly when deeper than the decoupling depth at $70 \mathrm{~km}$ but less so with distance from the slab top.

To gain an estimate of how variable temperature is within our full range of models, the standard deviation and total range in temperature is calculated at each point within the slab (Figures $4 \mathrm{a} 4 \mathrm{~b}$ ). Both the standard deviation and range in temperature increase with depth and are highest in the core of the slab, reaching 90 and $\sim 400{ }^{\circ} \mathrm{C}$ (respectively) at the Moho, $70 \mathrm{~km}$ beneath the decoupling depth. The slab surface, deeper than the decoupling depth, has a fairly constant standard deviation of $50-70{ }^{\circ} \mathrm{C}$ and range of $220-260{ }^{\circ} \mathrm{C}$. 

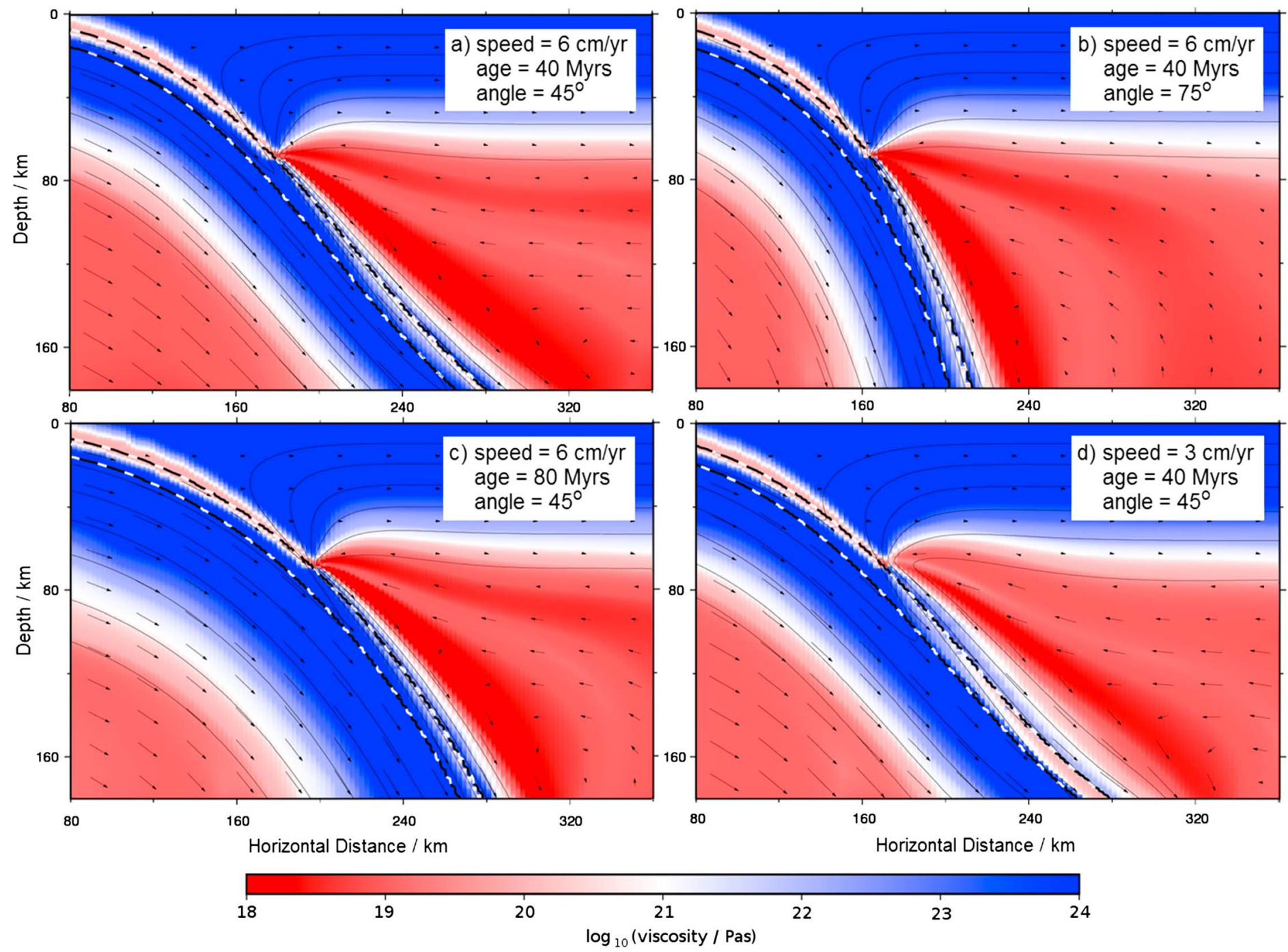

Figure 2. Model snapshots of four different model runs taken at the stage during which the PT paths of the slab are being measured; $200{ }^{\circ} \mathrm{C}$ isotherms are plotted with thin black lines, and the oceanic crust, which has a different density and rheology to the rest of the model, is outlined with a thicker black and white line. Arrows indicate relative velocity within each model. The decoupling point (at $70 \mathrm{~km}$ ) can be seen at the terminus of the weak, low viscosity zone along the top of the slab. Note that these snapshots have been cropped, and the right-hand side boundary in particular is at $x=700 \mathrm{~km}$, considerably further to the right than depicted here.

\subsection{Finding the Optimal ATPs at each Point in the Slab}

The temperature of the slab at 10-km intervals between 30 - and 150-km depths and at 1.5-km intervals from 1.5 to $15 \mathrm{~km}$ into the slab is extracted from the models and used to calculate the optimal values of $a, b$, and $c$, for these points in the slab. A subset of these optimal values is given in Table 2 along with how well the optimal ATP and original thermal parameter $(\Phi)$ perform.

For all points tested in the model, we are able to find a best fit thermal parameter with $r^{2}>0.9$ (Figure 5b) indicating that our ATPs are indeed good proxies for temperature in these models. Speed and age have a stronger control on slab temperature than angle at all points in the slab (Figure 5a). The slab seems to consist of two regions: primarily speed controlled $(b>a>c)$ closer to the slab top and deeper in the model and age controlled ( $a>>b$ and $c$ ) elsewhere. The boundary between them starts at the slab top at 5-10 km above the decoupling point and runs approximately diagonally down to the Moho at $30-40 \mathrm{~km}$ deeper than the decoupling depth. The original thermal parameter, $\Phi$, is observed to perform particularly poorly, relative to the adjusted definition, in this region close to the slab surface and decoupling depth, and also at the slab 


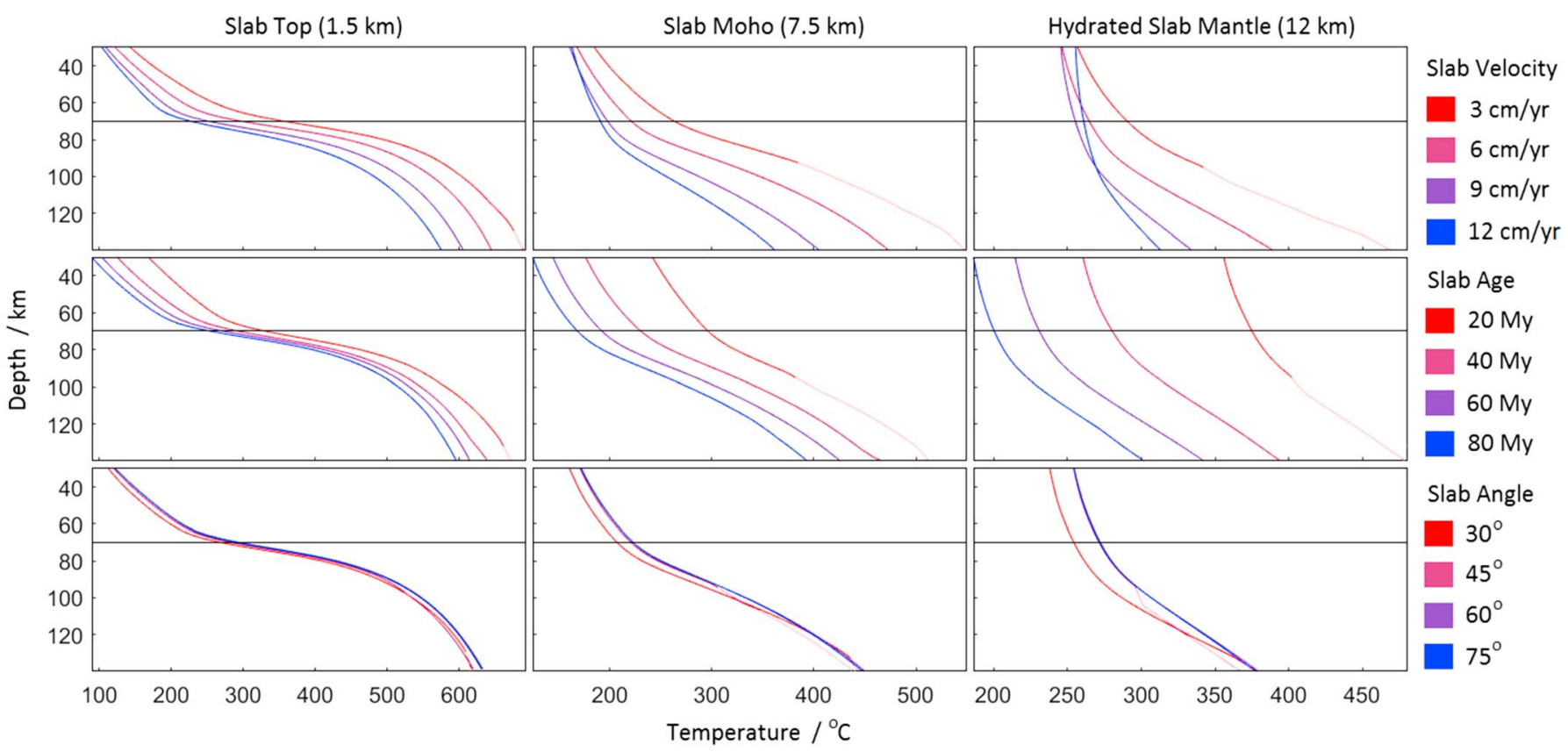

Figure 3. Averaged PT paths of models, which share a property (i.e., have the same speed, age, or angle). PT paths for models with like speeds are averaged and plotted as average curves in the plots on the top row. Similarly, like ages are shown on plots on the middle row and like angles on the bottom row. PT paths are given near the slab top (1.5 km from the top), the slab Moho (at $7.5 \mathrm{~km}$ ), and inside the slab mantle (at $12 \mathrm{~km}$ ). Faded parts of the curve indicate that one of the models used to calculate the curve did not run to this point due to solver convergence issues. As such, these faded sections should be treated as approximate but still give a good indication of how each property affects slab temperature. Exclusion of this data does not affect further analysis significantly.

surface deeper than the decoupling depth for $\sim 40 \mathrm{~km}$ (Figure 5c). It performs nearly as well as the adjusted definition, beneath the Moho, when more than $50 \mathrm{~km}$ deeper than the decoupling depth.

Figure 6 is a fuller, graphical representation of the results. The three faces of the cube represent the parameter space explored and, as explained in section 2.3, the optimal $r^{2}$ value should lie on one of these faces.

The width of the bullseye pattern on the cube gives an indication of how well constrained the optimal values

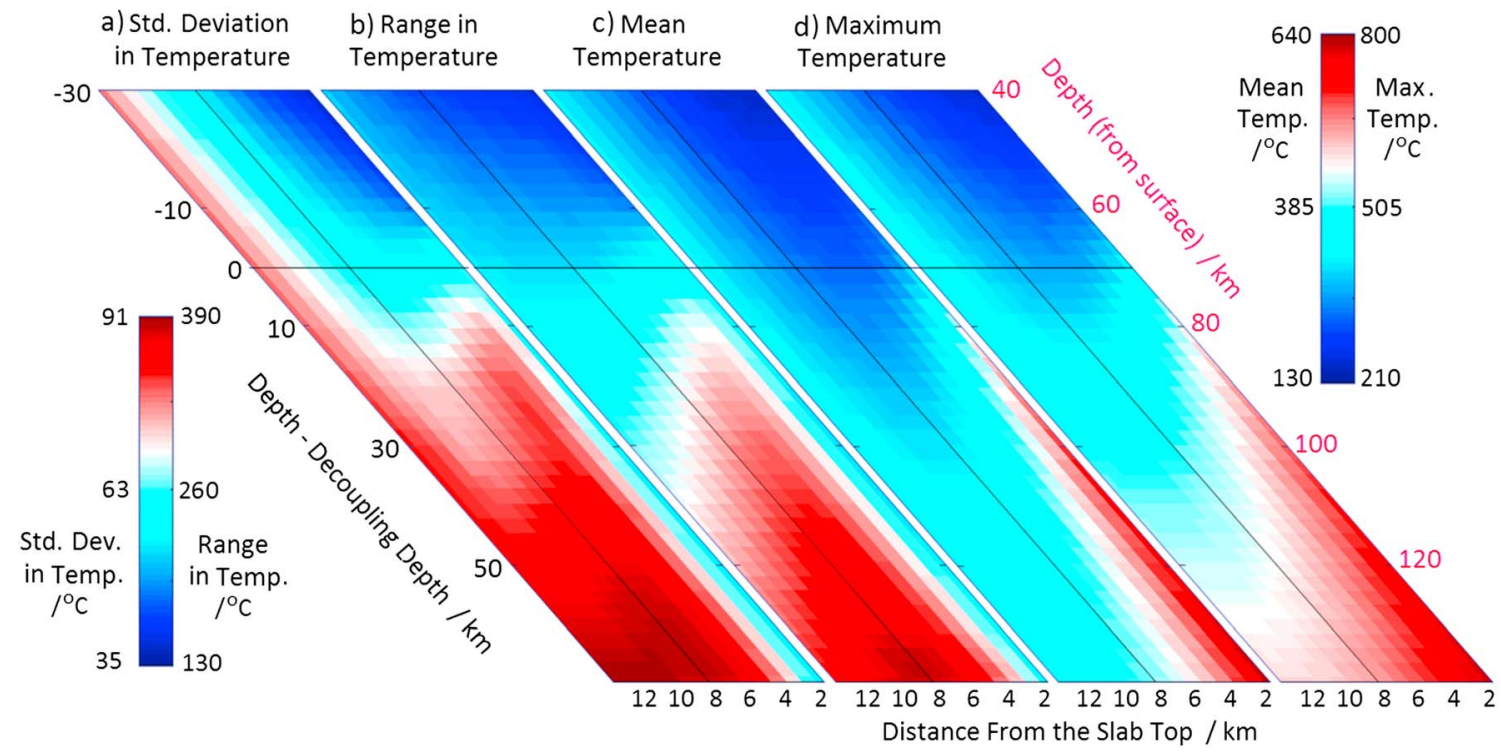

Figure 4. Slab cross sections displaying different information extracted from the models (black lines mark the decoupling depth and the Moho). (a) The standard deviation of the temperature between all the models ran. (b) The difference between the temperatures of the hottest and coldest models at that point. (c) The mean temperature of all the models. (d) The highest temperature found within all the models at each point. 
Table 2

The Set of Values of $a, b$, and $c$ (that define the ATP $=t^{a} v^{b} \sin \theta^{c}$ ) that Maximizes the $r^{2}$ Fit of $\log (A T P)$ for the Slab Temperature at Given Depth and Distance to the Slab Surface

\begin{tabular}{|c|c|c|c|c|c|c|c|c|c|}
\hline $\begin{array}{l}\text { Depth (km; } \\
\text { from surface) }\end{array}$ & $\begin{array}{l}\text { Distance from } \\
\text { slab top (km) }\end{array}$ & Optimal $a$ & Optimal $b$ & Optimal $c$ & $\begin{array}{c}\text { Highest } \\
\text { achieved } r^{2}\end{array}$ & $\begin{array}{c}r^{2} \text { using } \\
\text { original T.P. }(\Phi)\end{array}$ & $\begin{array}{l}r^{2} \text { with } \\
\text { age only }\end{array}$ & $\begin{array}{c}r^{2} \text { with } \\
\text { speed only }\end{array}$ & $\begin{array}{c}r^{2} \text { with } \\
\text { angle only }\end{array}$ \\
\hline 50 & 1.5 & 1 & 0.8 & 0.3 & 0.95 & 0.78 & 0.55 & 0.38 & 0.02 \\
\hline 50 & 7.5 & 1 & 0.2 & 0.1 & 0.98 & 0.61 & 0.93 & 0.06 & 0.01 \\
\hline 50 & 12 & 1 & 0.1 & 0 & 0.99 & 0.45 & 0.99 & 0 & 0.01 \\
\hline $70^{\mathrm{a}}$ & 1.5 & 0.6 & 1 & 0.5 & 0.94 & 0.70 & 0.24 & 0.67 & 0.03 \\
\hline $70^{a}$ & 7.5 & 1 & 0.4 & 0.1 & 0.98 & 0.71 & 0.83 & 0.15 & 0.01 \\
\hline $70^{a}$ & 12 & 1 & 0.1 & 0 & 0.99 & 0.51 & 0.98 & 0.01 & 0.01 \\
\hline 90 & 1.5 & 0.5 & 1 & 0.3 & 0.93 & 0.71 & 0.18 & 0.73 & 0.01 \\
\hline 90 & 7.5 & 1 & 0.8 & 0.2 & 0.95 & 0.81 & 0.56 & 0.39 & 0.01 \\
\hline 90 & 12 & 1 & 0.2 & 0 & 0.99 & 0.61 & 0.93 & 0.05 & 0.01 \\
\hline 110 & 1.5 & 0.6 & 1 & 0.2 & 0.92 & 0.76 & 0.22 & 0.67 & 0.01 \\
\hline 110 & 7.5 & 0.9 & 1 & 0.1 & 0.95 & 0.84 & 0.38 & 0.53 & 0 \\
\hline 110 & 12 & 1 & 0.4 & 0.1 & 0.97 & 0.71 & 0.81 & 0.14 & 0.01 \\
\hline 130 & 1.5 & 0.7 & 1 & 0.1 & 0.93 & 0.79 & 0.27 & 0.65 & 0 \\
\hline 130 & 7.5 & 0.8 & 1 & 0.1 & 0.95 & 0.87 & 0.33 & 0.61 & 0 \\
\hline 130 & 12 & 1 & 0.6 & 0.1 & 0.97 & 0.84 & 0.68 & 0.28 & 0 \\
\hline
\end{tabular}

Note. $r^{2}$ values are reported for this best fit for this ATP, the fit for the original thermal parameter, and the fit for plots of slab temperature versus each parameter individually. ATP = adjusted thermal parameter.

${ }^{a_{70}} \mathrm{~km}$ is the decoupling depth.

for the exponents are. If the point with the highest $r^{2}$ lies on the top face, then angle is the most important parameter-age on the left face and speed on the right face. The actual plots of $T$ versus optimal $\log _{10}(A T P)$, with best fit linear regression lines overlain, are also presented in Figure 6. These demonstrate that a linear relationship between $T$ and $\log _{10}$ (optimal $A T P$ ) is a good first-order fit.

\subsection{Decoupling Depth Study}

In order to investigate the effect of decoupling depth, we ran the same study but with a fixed subduction angle of $45^{\circ}$ and a variable decoupling depth $\left(d_{\text {decoupling }}=40,60,80\right.$, and $\left.100 \mathrm{~km}\right)$. Angle was, in this case,

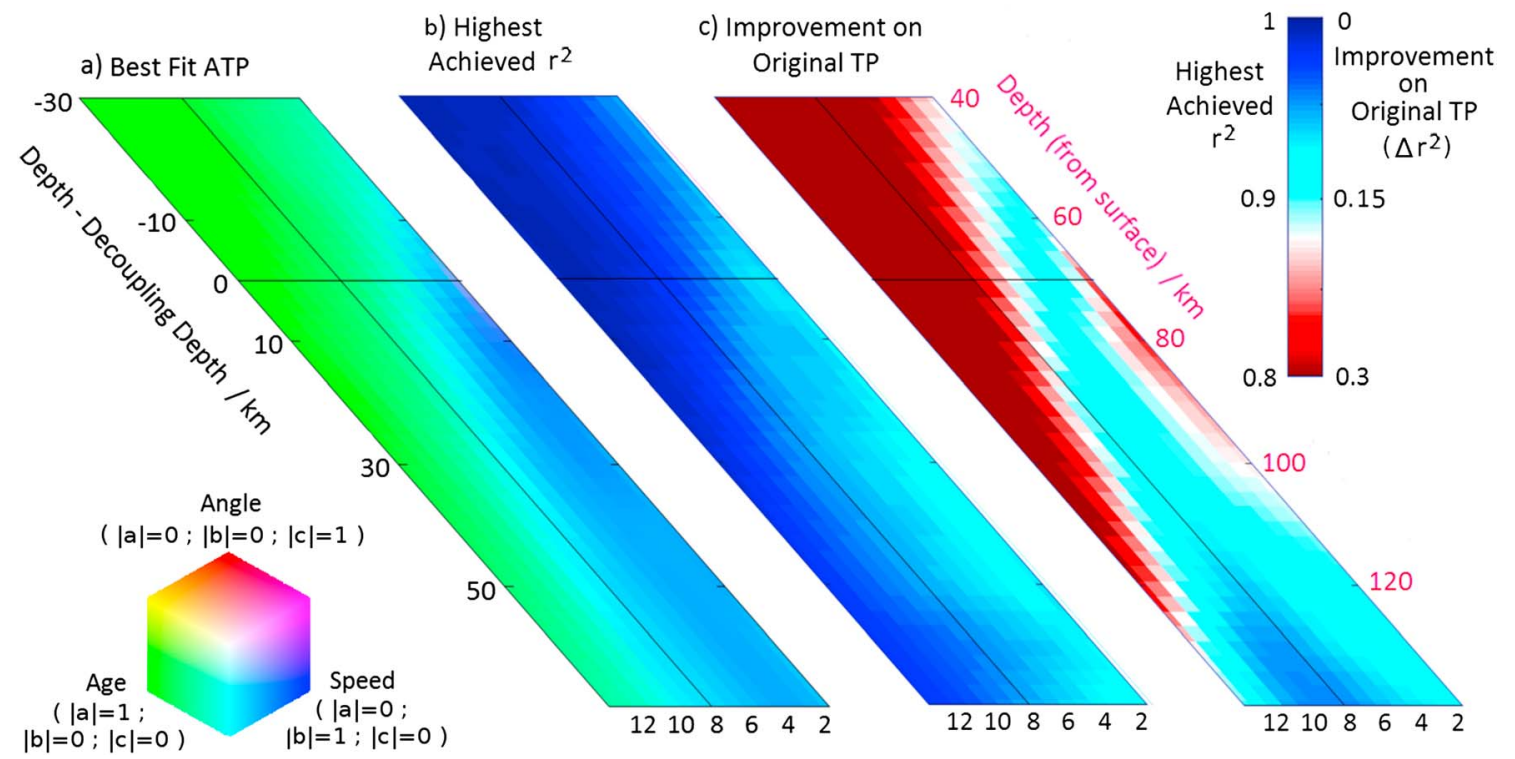

Figure 5. Slab cross sections displaying different information extracted from the models (black lines mark the decoupling depth and the Moho). (a) The optimal values of $a$ (age), $b$ (speed), and $c$ (angle) plotted using RGB color (see the key in the bottom left). (b) The $r^{2}$ value of a plot of slab temperature and the logarithm of the optimal adjusted thermal parameter. (c) The difference between the highest achieved $r^{2}$ value and the $r^{2}$ value resulting from the use of the original thermal parameter, $\phi$. ATP = adjusted thermal parameter. 


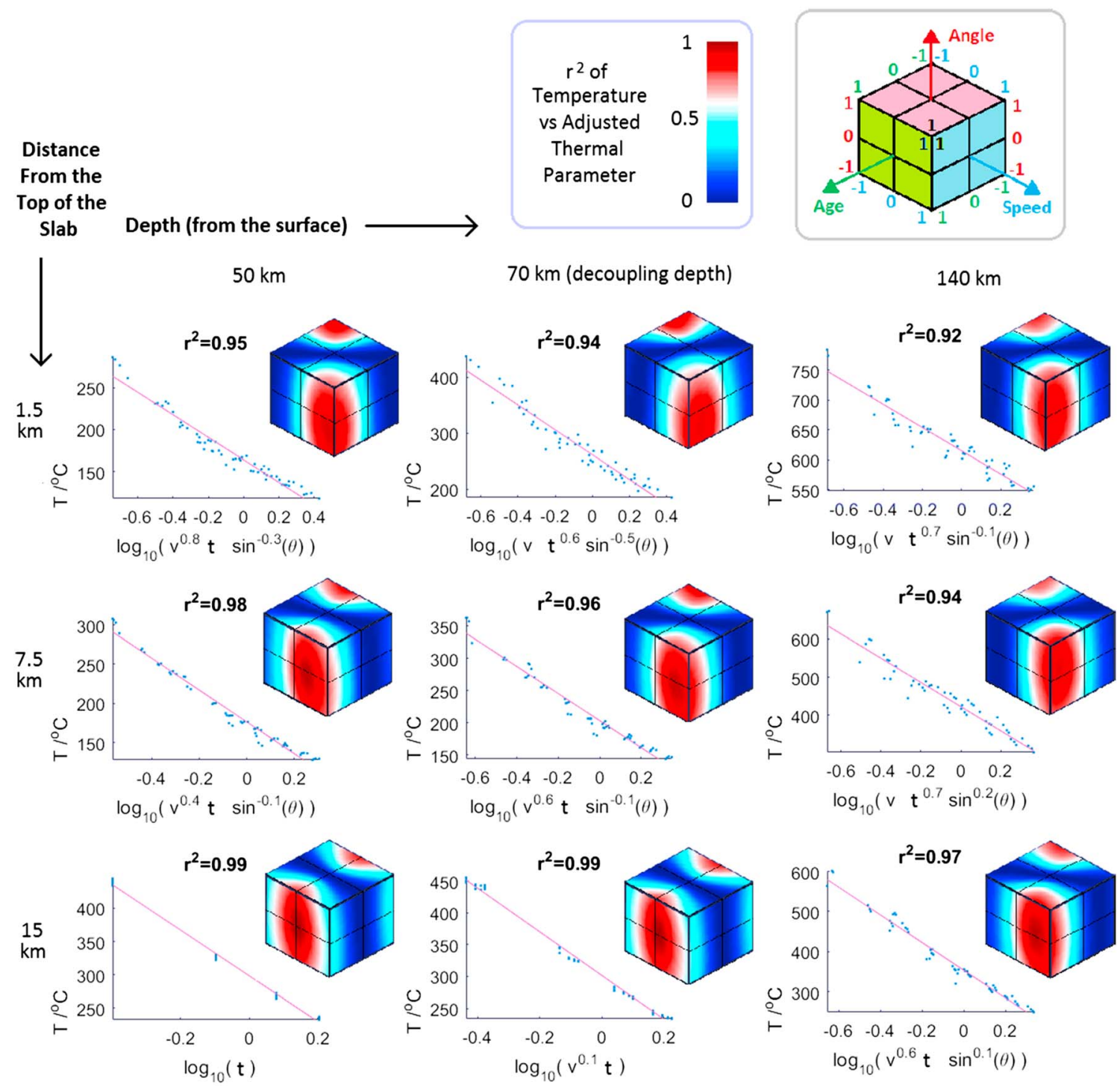

Figure 6. The colored cubes are a graphical representation of the full explored parameter space. The left face is $a=1,-1<b<1, \quad-1<c<1$, right face is $b=1$, $-1<c<1, \quad-1<a<1$, and top face is $c=1, \quad-1<a<1, \quad-1<b<1$; see the key to the top right of these plots to see this pictorially. Red colors represent values of $a, b$, and $c$, which yield high $r^{2}$ values in plots of the logarithm of the resultant ATP and temperature for certain points in the model (50-, 70-, 90-, and $140-\mathrm{km}$ depths and $1.5,7.5$, and $15 \mathrm{~km}$ from the slab surface). The "optimal" plots, which yield the highest $r^{2}$, are given for each cube to their bottom left with the lines of best fit plotted and the resultant $r^{2}$ given. An intuitive way to interpret the cube plots is as follows: If the center of the red "bullseye" falls on the left face of the cube, then age has the strongest control on temperature, speed on the right face and angle on the top face. The width of the bullseye gives an indication of how quickly $r^{2}$ deteriorates with distance from the optimal values of $a, b$, and $c$.

chosen to be fixed as it was observed to have the weakest effect on slab temperature throughout the slab. The ATP in this study is now therefore defined as follows:

$$
A T P=t^{a} v^{b} d_{\text {decoupling }}^{c} .
$$

The $a, b, c$ parameter space is explored for the best fit ATP just as before. Figure 7 presents the results from this study in a similar form to Figure 5. Depth is measured from the surface. The decoupling depth has a dominant effect within the depth range over which the decoupling depth is varied $(40-100 \mathrm{~km})$, inside the slab crust (Figure 7a). In this region, the decoupling depth is almost entirely responsible for a variation in temperature of up to $300{ }^{\circ} \mathrm{C}$ (Figure 7d). As a result, the best fit ATP using just age and speed performs very poorly in this region (Figure 7c). Once deeper than $100 \mathrm{~km}$, this dependence diminishes with depth, with 


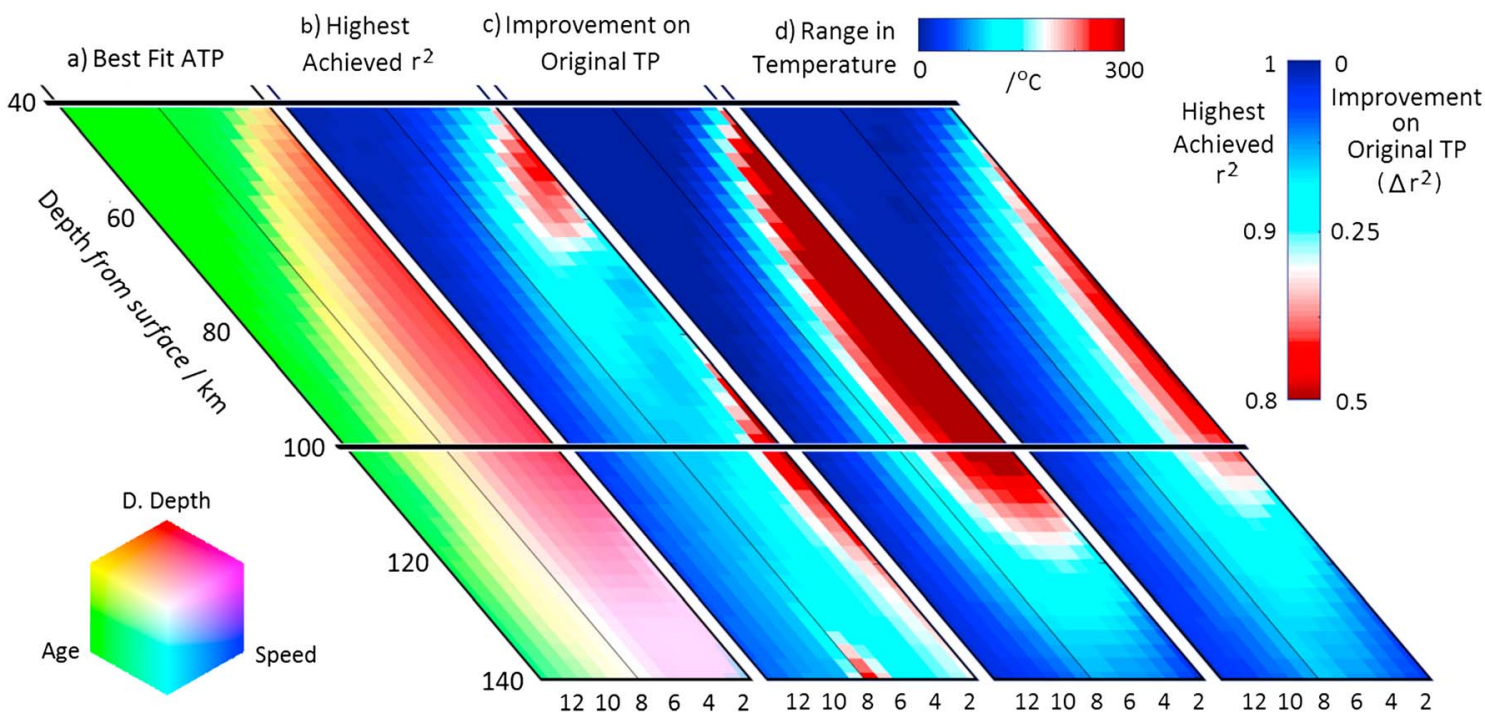

Figure 7. As in Figure 5 but representing the results for the decoupling depth study, in which decoupling depth was varied instead of subduction angle. Depth is only given relative to the surface. The range over which decoupling depth is varied is 40 to $100 \mathrm{~km}$. This is highlighted by the thick black horizontal lines. ATP now refers to an adjusted thermal parameter formulated with decoupling depth instead of angle (see main text). ATP $=$ adjusted thermal parameter.

speed and decoupling depth having roughly equal effect in the slab crust at 140-km depth. Behavior in the previously "age-controlled" region (in the slab mantle) remains roughly the same, indicating that decoupling depth has a relatively minor effect on the temperatures in this part of the slab.

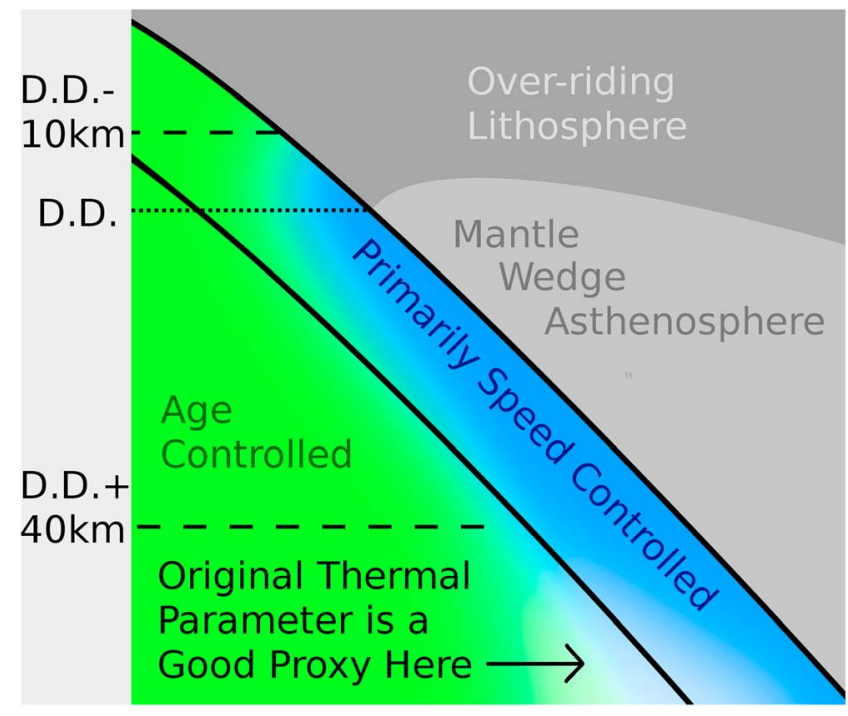

Figure 8. A schematic of the first-order results of the main study. The top of the slab and the slab Moho (at $7.5 \mathrm{~km}$ ) are depicted as black lines. The decoupling depth (D.D.) coincides with the shallowest point of the mantle wedge asthenosphere (light gray). The green and blue regions are the agecontrolled and primarily speed-controlled regions of the slab (see main text), respectively. Horizontal dashed lines represent important depths: D.D., the decoupling depth; D.D. $-10 \mathrm{~km}$, shallower than which the whole slab's temperature is determined by its age; and D.D. $+40 \mathrm{~km}$, deeper than which the original thermal parameter starts to become a good indicator of slab temperatures (starting in the core of the slab, as indicated by the fading of the colors to white).

\section{Discussion}

\subsection{Improving on the Thermal Parameter $\phi$}

The original definition of the thermal parameter has previously been found to perform well for slab temperatures at 240-km depth (Syracuse et al., 2010). Our results confirm this: For the slab Moho, at depths $>140 \mathrm{~km}$, the ATP improves very little on the original thermal parameter, with an increase in $r^{2}$ of only <0.1 (Figure 5c). Syracuse et al. (2010) found that the original thermal parameter also works well at $30 \mathrm{~km}$; however, we observe that all parts of the slab shallower than $\sim 60 \mathrm{~km}(10 \mathrm{~km}$ above the decoupling point) are dependent on age and little else (Figure 5a). Between these regions, the relative importance of age and speed is more complex, with angle having more of a second-order effect. To simplify, there are effectively three regions (Figure 8) with blurred boundaries:

$$
\begin{aligned}
& \text { Age controlled : } T \propto \log \left(t^{-1}\right), \\
& \text { Primarily speed controlled : } T \propto \log \left(v^{-1} t^{-k}\right) ; k \sim 0.5 \text {. }
\end{aligned}
$$

The approximate distance from the line that separates the primarily speed-controlled region from the age-controlled region and the slab top is actually the characteristic conduction length scale (Turcotte \& Schubert, 2014) of a slab that has been heated from the top (starting at $10 \mathrm{~km}$ above the decoupling point) and moving at $7.5 \mathrm{~cm} /$ year: the average speed used in our study. This is expected, since age affects the initial thermal profile of slabs and during subsequent subduction; the only way the slab warms from the top is by thermal diffusion from the mantle wedge. Faster slabs will have colder tops relative to slower slabs at the same distance from the decoupling point, and, as heat diffuses into the 
slab from this point, temperature of the deeper parts of the slab will begin to develop a stronger speed dependence.

Of the slab parameters, angle has the weakest effect on slab temperatures throughout the slab. The lack of angle dependence at depths less than the decoupling depth may be due, in part, to the fact that slabs with different dips have similar steady state geometries in this region. Despite this, below the decoupling point, one would still expect angle to have a similar effect to slab speed. However, what we find is that the small effect angle does have (and only near the decoupling point) is opposite in sense: Shallow slabs have colder slab tops. This appears to be because, in the shallower cases, the mantle wedge flow which brings heat to the top of the slab is restricted, particularly in the (narrower) mantle wedge corner.

A property not included in the original definition of the thermal parameter is decoupling depth, and we have shown that the effect of decoupling depth is potentially strong. When considering temperature with depth from the surface, decoupling depth dominates within the depth range over which it is varied, down to $40 \mathrm{~km}$ deeper than this range and all within the previously primarily speed-controlled region. Temperatures in the previously age-controlled region remain primarily age controlled.

However, it has been suggested that decoupling depths around the world do not vary significantly from 70$80 \mathrm{~km}$ (Furukawa, 1993; Wada \& Wang, 2009). If the decoupling depth is indeed nearly constant, its effect is likely negligible and one would expect the slab parameters age and speed to have the dominant effect on slab temperatures (Figure 8). Turner and Langmuir (2015) indicate that the nature of the overriding plate may play a more significant role in determining the geochemistry of arc lavas, though whether this is due to variable decoupling depth is uncertain and perhaps an avenue for further study.

\subsection{Comparison With Previous Work}

Using the slab top geotherms, presented in Figure 3, allows us to cross check with two important numerical modeling studies: Gerya et al. (2002) and van Keken et al., 2002. These two studies use different modeling approaches. Our method of plate decoupling is closest to van Keken et al., 2002, the same model setup subsequently used by Syracuse et al. (2010), and as a result our calculated slab top geotherms follow a similar PT path, but on the cooler end (our mean lies $100^{\circ} \mathrm{C}$ below that of van Keken et al., 2002), in part due to our exclusion of adiabatic heating and perhaps in part, due to the fact that our "slab top" is actually at $1.5 \mathrm{~km}$ into the slab. It has been shown that these geotherms are already too cold to fit prograde PT paths of most exhumed ultrahigh-pressure-metamorphic rock (Penniston-Dorland et al., 2015), although this may be due to the fact that the exhumation mechanisms necessary for their preservation require anomalous subduction, for example, slab breakoff during continental collision or that there is a preservation bias toward hot subduction zones (Abers et al., 2017). Penniston-Dorland et al. (2015) also analyze the effect of speed, age, and angle within these modeling results and demonstrate that slab dip has by far the least important effect on slab top temperature, a result we recreate. Age affects slab top temperatures by $\sim 200{ }^{\circ} \mathrm{C}$ in both the Gerya et al. (2002) and van Keken et al. (2002) studies, roughly consistently at all depths. We observe the same consistency but overall less variation $\left(\sim 100^{\circ} \mathrm{C}\right)$. Where our results differ mostly is in the effect of speed on slab top temperatures, and this is also something that differs between Gerya et al. (2002) and van Keken et al. (2002). Shallower than the decoupling depth, we agree with both studies that slower slabs have hotter tops. We demonstrate that the effect of speed increases with depth and that deeper than the decoupling depth, it has the dominant effect, with slower slabs being hotter. However, in this region (the slab top beneath the decoupling point), the results from van Keken et al. (2002) show that speed has a negligible effect and the results of Gerya et al. (2002) show a reversal in the effect of speed at $\sim 50 \mathrm{~km}$. Neither study includes shear heating fully (van Keken et al. (2002) include shear heating along the decoupled interface only), and preliminary work during our investigation indicated that shear heating increases slab top temperatures by $<40{ }^{\circ} \mathrm{C}$ in the fastest model and was therefore excluded from our models also. As such, this discrepancy likely arises from elsewhere. Magni et al. (2014) actually conclude that faster slabs have hotter tops due to more vigorous convection in the mantle wedge. However, in their models, at $2 \mathrm{~km}$ from the slab top, this is no longer the case. This suggests that the results of this study are not necessarily at odds with the results of previous work; rather, the simple model depicted in Figure 8 is insufficient to describe the slab thermal structure within a kilometer from the slab surface. This topmost kilometer is likely geodynamically complex, with the presence of small-scale deformation processes arising from the mechanical interaction between the slab and overriding plate or mantle wedge. 


\subsection{Geochemical Implications}

In a simplified view, a three-layer slab (sediments, igneous crust, and hydrated slab lithospheric mantle) supplies the overlying mantle wedge and the deep mantle with different geochemical components at different depths within the subduction system. The depth of element distillation is primarily controlled by the shape of the isotherms and the overall thermal structure of the slab (Bouilhol et al., 2015). If we consider that the subducting slab lithologies are water saturated, the sediments will be the first to dehydrate, closely followed by the igneous mafic crust, with the hydrated slab mantle being the last to dehydrate, possibly carrying water to the deep mantle (Schmidt \& Poli, 2014).

These overall aspects of slab devolatilization can be put into the perspective of our results, presented in Figure 8, and, using them, we should be able to predict how dehydration depends on slab age, speed, and angle (and decoupling depth). Mafic crust is predicted to fully dehydrate between 70 and $>300 \mathrm{~km}$, and this depends primarily on temperature (Poli \& Schmidt, 2002). We show that slab temperatures are predominantly controlled by age shallower than $70 \mathrm{~km}$. One should therefore expect that the extreme case (where the crust has fully dehydrated by $70 \mathrm{~km}$ and has lost its fluid content completely to the forearc) to occur only during subduction of the youngest slabs and largely regardless of speed or angle. In the coldest slabs, where significant amounts of hydrated phases would be expected to persist past the decoupling depth and fluids are transported to the subarc region, one should expect the depth of crustal dehydration to be primarily speed controlled. However, if decoupling depth is shown to vary significantly, then this should actually control crustal dehydration more strongly than the slab parameters in these colder cases. If dehydration is early enough, this can be too soon for the fluids to be transported to the melt generating region of the mantle wedge and as such would be simply lost to the forearc (Abers et al., 2017; Hyndman \& Peacock, 2003). This is important as these first fluids would carry with them the most fluid mobile elements, depleting them in the arc magma source (Savov et al., 2007).

The primary dehydration reaction in the slab mantle, and predicted to be the most significant flux of water from the slab, is the breakdown of antigorite serpentine, a reaction that is highly temperature dependent (Ulmer \& Trommsdorff, 1995). At $\sim 120 \mathrm{~km}$ (50 km below the decoupling point) this reaction occurs at $650{ }^{\circ} \mathrm{C}$. This temperature is only achieved in the hottest models; on average, the slab is still too cool shallower than $150 \mathrm{~km}$. As such, antigorite breakdown will almost exclusively occur in a region of the slab, which is well characterized by the original definition of the thermal parameter. As water transport to the deep mantle is mainly controlled by this hydrated portion of the slab mantle (Magni et al., 2014; Rüpke et al., 2004), it is likely that the original thermal parameter is a good indicator for the efficiency of deep water transport. Previous studies have also found that both age and speed play an important role in deep water recycling in the same sense (Magni et al., 2014; van Keken et al., 2011). If decoupling depth is shown to vary, the dehydration of the slab mantle will only be slightly affected by decoupling depth and only in the hottest (youngest) cases.

The fluid-present solidus of a typical subducted metasediment lies at $\sim 700{ }^{\circ} \mathrm{C}$ at the decoupling depth (70-80 km) and increases to $\sim 800{ }^{\circ} \mathrm{C}$ by $140 \mathrm{~km}$ (Poli \& Schmidt, 2002). These temperatures are not reached at the top of our average subduction zone (measuring at $1.5 \mathrm{~km}$ means that we may be underestimating slightly although sediment layers on the top of subducted plates are typically 0.5-2 km thick [Clift \& Vannucchi, 2004]). However, the hottest models do reach these temperatures within the speed-controlled region (no models reach this temperature range outside this region). The fluid-present solidus of mid-ocean ridge basalt is similar but slightly higher than the fluid-present solidus of the metasediment (Nichols et al., 1994; Poli \& Schmidt, 2002), and therefore, we would only expect the very topmost mafic crust to melt and perhaps only in the slowest subduction settings and where sediment cover is thin.

Fluid absent melting occurs via the breakdown of hydrous phases at temperatures higher than those recorded in our models (Johnson \& Plank, 2000; Skjerlie \& Douce, 2002). Bouilhol et al. (2015) demonstrate that the crust should be devoid of fluid by the time it reaches melting conditions and fluid-present melting is only achieved via fluxing by fluids derived from the slab mantle below. As discussed above, at what depth the slab mantle dehydrates is dependent on the thermal parameter, and only shallow enough to be within our model domain for the youngest slabs. This may imply that a slab needs to be young as well as subducting slowly to enable mafic crust or sediment melting. However, melting of crustal material may be enhanced, 
and fluid-absent melting made possible, by the formation of crustal plumes or diapirs (Behn et al., 2011). This is further discussed in section 4.4.

Perhaps sediment melting does occur on Earth today as indicated by the higher than expected concentrations of the fluid incompatible elements thorium and beryllium in arc lavas (Behn et al., 2011; Johnson \& Plank, 2000). It has also been suggested that the mafic crust may also partially melt, giving rise to the rare "adakitic" signature (Defant \& Drummond, 1990). Our results indicate, following our previous reasoning, that one should expect sediment and/or crustal melting to be more likely in the slowest subduction zones today, although this is perhaps only for slabs that are also young, unless another mechanism facilitates fluid-absent melting. Importantly, the likelihood of sediment/crustal melting should not depend on slab dip.

\subsection{Other Implications}

The seismicity of slabs is known to depend heavily on their thermal structure (Ruff \& Kanamori, 1980). Strong correlations between features of deep $(>300 \mathrm{~km})$ earthquakes (specifically $b$ values or number of aftershocks) and the original definition of the thermal parameter have been demonstrated (Kirby et al., 1996; Wiens \& Gilbert, 1996) as well as the maximum depth of earthquakes (Gorbatov \& Kostoglodov, 1997). We have shown here that the original thermal parameter should indeed correlate well with the occurrence/intensity of any thermally controlled process at these depths. It has also been shown that the seismic moment of the largest characteristic earthquakes within a particular subduction section correlates primarily with just slab age (Peterson \& Seno, 1984). We propose that this correlation could be due to differences in thermal structure above the decoupling point, which indeed should be slab age dependent according to the results of this study.

England et al. (2004) demonstrate that the depth to the top of the zone of intermediate-depth seismicity (interpreted to be the slab top) directly below volcanic arcs inversely correlates with subduction speed and Syracuse and Abers (2006) find that the depth to the slab top correlates with slab dip but nothing else. We find that faster slabs have colder tops (so should actually dehydrate deeper) and that slab top temperature is less dependent on slab dip than speed or age. Therefore, coupling either of these results with our findings lends strength to the argument that arc position is controlled by factors other than slab thermal structure (England \& Katz, 2010; Perrin et al., 2016). Syracuse and Abers (2006) also find that the width of the seismogenic zone correlates with slab age alone. Given that slab seismicity is believed to be thermally controlled, our results lead to the prediction that this should indeed be solely age dependent.

The formation of crustal plumes or diapirs has been suggested to occur in subduction zones today (Gerya \& Yuen, 2003) and subsequent relamination, or underplating, of the overriding plate with slab-derived material (Hacker et al., 2011). This dynamic process would have a profound effect on arc magmatism (Marschall \& Schumacher, 2012) and could explain a high temperature sediment melt signature, which is pervasive in many subduction zones (Behn et al., 2011). Maunder et al. (2016) demonstrate that this process is enhanced under hotter, Archean conditions and also under modern Earth conditions during slow subduction, although age appears less important. In light of the results presented here, the dependence of this behavior on subduction speed alone makes sense as these plumes form from the slab crust, below the decoupling point, in the speed-controlled region. We would therefore expect to see evidence of relamination occurring predominantly in the Earth's slowest subduction zones.

\section{Conclusions}

We conducted a parametric study using a 2-D, dynamic, thermomechanical model of subduction to investigate the effects of varying slab age, trench normal convergence rate, and slab dip on the thermal structure of the slab. In particular, we evaluate how well the thermal parameter, $\phi$, performs as an indicator of slab temperature at different points within the slab. We find that beyond $50 \mathrm{~km}$ deeper than the decoupling depth (the point at which the overriding mantle becomes coupled to the slab), the thermal parameter performs well for internal slab temperature (slab mantle and increasingly the slab crust as depth increases). We adjust this thermal parameter by modulating the importance of the slab speed, age, and angle to generate a more effective, empirically derived temperature indicator. By doing this, we find that the temperature dependence of the remainder of the slab can be described well by dividing the slab into two regions: age controlled and primarily speed controlled. To first order, the age-controlled region consists of the whole slab mantle and 
both the mantle and crust shallower than the decoupling depth. Within this region, temperatures are determined almost exclusively by the age of the slab: younger slabs being hotter. The primarily speed-controlled region approximately consists of the slab crust deeper than the decoupling depth. The temperature within this region is primarily controlled by speed and secondarily controlled by slab age: Slower, younger slabs are hotter.

Crucially for melt generation, at subarc depths $(\sim 100 \mathrm{~km})$, the slab mantle temperature is almost exclusively age controlled and the slab crust temperature is primarily speed controlled (although we do not model the top $\sim 1 \mathrm{~km}$ of the slab and, as such, we recognize that this region may behave differently). In addition, our results indicate that any early devolatilization (shallower than the decoupling depth) should depend on slab age alone and the amount of deep water transport (in the core of the slab) should correlate well with the original definition of the thermal parameter.

We also investigate the effect of varying the decoupling depth. This has a dominant effect on slab temperatures, overwhelming the effect of slab parameters, but only within the slab crust and to $40 \mathrm{~km}$ deeper than the maximum decoupling depth. However, whether decoupling depth is actually variable in reality is debated.

\section{Acknowledgments}

This study was supported by the European Research Council (ERC StG 279828). This work made use of the computational facilities of Hamilton HPC at Durham University and N8 HPC provided and funded by the N8 consortium and EPSRC (Grant $\mathrm{EP} / \mathrm{K} 000225 / 1)$. V. M. also acknowledges support from the Research Council of Norway through its Centres of Excellence funding scheme, Project 223272. We also thank the three anonymous reviewer and Editor Thorsten Becker for their constructive comments and suggestions, which greatly improved this manuscript. All the data used are listed in the references or archived in the following repository: Zenodo.org, record 2530260 (DOI: $10.5281 /$ zenodo.2530260).

\section{References}

Abers, G. A., van Keken, P. E., \& Hacker, B. R. (2017). The cold and relatively dry nature of mantle forearcs in subduction zones. Nature Geoscience, 10(5), 333-337. https://doi.org/10.1038/ngeo2922

Agrusta, R., Goes, S., \& van Hunen, J. (2017). Subducting-slab transition-zone interaction: Stagnation, penetration and mode switches. Earth and Planetary Science Letters, 464, 10-23. https://doi.org/10.1016/j.epsl.2017.02.005

Arcay, D., Tric, E., \& Doin, M. P. (2007). Slab surface temperature in subduction zones: Influence of the interplate decoupling depth and upper plate thinning processes. Earth and Planetary Science Letters, 255(3-4), 324-338. https://doi.org/10.1016/j. epsl.2006.12.027

Behn, M. D., Kelemen, P. B., Hirth, G., Hacker, B. R., \& Massonne, H. J. (2011). Diapirs as the source of the sediment signature in arc lavas. Nature Geoscience, 4(9), 641-646. https://doi.org/10.1038/ngeo1214

Bouilhol, P., Magni, V., van Hunen, J., \& Kaislaniemi, L. (2015). A numerical approach to melting in warm subduction zones. Earth and Planetary Science Letters, 411, 37-44. https://doi.org/10.1016/j.epsl.2014.11.043

Clift, P., \& Vannucchi, P. (2004). Controls on tectonic accretion versus erosion in subduction zones: Implications for the origin and recycling of the continental crust. Reviews of Geophysics, 42, RG2001. https://doi.org/10.1029/2003RG000127

Cooper, L. B., Ruscitto, D. M., Plank, T., Wallace, P. J., Syracuse, E. M., \& Manning, C. E. (2012). Global variations in H2O/Ce: 1. Slab surface temperatures beneath volcanic arcs. Geochemistry, Geophysics, Geosystems, 13, Q03024. https://doi.org/10.1029/2011GC003902

Currie, C. A., Wang, K., Hyndman, R. D., \& He, J. (2004). The thermal effects of steady-state slab-driven mantle flow above a subducting plate: The Cascadia subduction zone and backarc. Earth and Planetary Science Letters, 223(1-2), 35-48. https://doi.org/10.1016/j. epsl.2004.04.020

Defant, M. J., \& Drummond, M. S. (1990). Derivation of some modern arc magmas by melting of young subducted lithosphere. Nature, 347(6294), 662-665. https://doi.org/10.1038/347662a0

England, P., Engdahl, R., \& Thatcher, W. (2004). Systematic variation in the depths of slabs beneath arc volcanoes. Geophysical Journal International, 156(2), 377-408. https://doi.org/10.1111/j.1365-246X.2003.02132.x

England, P., \& Wortel, R. (1980). Some consequences of the subduction of young slabs. Earth and Planetary Science Letters, 47(3), $403-415$. https://doi.org/10.1016/0012-821X(80)90028-X

England, P. C., \& Katz, R. F. (2010). Melting above the anhydrous solidus controls the location of volcanic arcs. Nature, 467(7316), 700-703. https://doi.org/10.1038/nature09417

Forsyth, D., \& Uyeda, S. (1975). On the relative importance of the driving forces of plate motion. Geophysical Journal of the Royal Astronomical Society, 43(1), 163-200. https://doi.org/10.1111/j.1365-246X.1975.tb00631.x

Furukawa, Y. (1993). Depth of the decoupling plate interface and thermal structure under arcs. Journal of Geophysical Research, 98(B11), 20,005-20,013. https://doi.org/10.1029/93JB02020

Gerya, T. V., Stöckhert, B., \& Perchuk, A. L. (2002). Exhumation of high-pressure metamorphic rocks in a subduction channel: A numerical simulation. Tectonics, 21(6), 1056. https://doi.org/10.1029/2002TC001406

Gerya, T. V., \& Yuen, D. A. (2003). Rayleigh-Taylor instabilities from hydration and melting propel 'cold plumes' at subduction zones. Earth and Planetary Science Letters, 212(1-2), 47-62. https://doi.org/10.1016/S0012-821X(03)00265-6

Gorbatov, A., \& Kostoglodov, V. (1997). Maximum depth of seismicity and thermal parameter of the subducting slab: General empirical relation and its application. Tectonophysics, 277(1-3), 165-187. https://doi.org/10.1016/S0040-1951(97)00084-X

Hacker, B. R., Kelemen, P. B., \& Behn, M. D. (2011). Differentiation of the continental crust by relamination. Earth and Planetary Science Letters, 307(3-4), 501-516. https://doi.org/10.1016/j.epsl.2011.05.024

Helffrich, G., \& Brodholt, J. (1991). Relationship of deep seismicity to the thermal structure of subducted lithosphere. Nature, 353(6341), 252-255. https://doi.org/10.1038/353252a0

Heuret, A., \& Lallemand, S. (2005). Plate motions, slab dynamics and back-arc deformation. Physics of the Earth and Planetary Interiors, 149(1-2), 31-51. https://doi.org/10.1016/j.pepi.2004.08.022

Hyndman, R. D., \& Peacock, S. M. (2003). Serpentinization of the forearc mantle. Earth and Planetary Science Letters, 212(3-4), 417-432. https://doi.org/10.1016/S0012-821X(03)00263-2

Johnson, M. C., \& Plank, T. (2000). Dehydration and melting experiments constrain the fate of subducted sediments. Geochemistry, Geophysics, Geosystems, 1(12). https://doi.org/10.1029/1999GC000014

Kessel, R., Schmidt, M. W., Ulmer, P., \& Pettke, T. (2005). Trace element signature of subduction-zone fluids, melts and supercritical liquids at 120-180 km depth. Nature, 437(7059), 724-727. https://doi.org/10.1038/nature03971 
Kirby, S. H., Stein, S., Okal, E. A., \& Rubie, D. C. (1996). Metastable mantle phase transformations and deep earthquakes in subducting oceanic lithosphere. Reviews of Geophysics, 34(2), 261-306. https://doi.org/10.1029/96RG01050

Lallemand, S., Heuret, A., Faccenna, C., \& Funiciello, F. (2008). Subduction dynamics as revealed by trench migration. Tectonics, 27, TC3014. https://doi.org/10.1029/2007TC002212

Magni, V., Bouilhol, P., \& van Hunen, J. (2014). Deep water recycling through time. Geochemistry, Geophysics, Geosystems, 15, 4203-4216. https://doi.org/10.1002/2014GC005525

Marschall, H. R., \& Schumacher, J. C. (2012). Arc magmas sourced from mélange diapirs in subduction zones. Nature Geoscience, 5(12), 862-867. https://doi.org/10.1038/ngeo1634

Maunder, B., Van Hunen, J., Magni, V., \& Bouilhol, P. (2016). Relamination of mafic subducting crust throughout Earth's history. Earth and Planetary Science Letters, 449, 206-216. https://doi.org/10.1016/j.epsl.2016.05.042

McKenzie, D. P. (1969). Speculations on the consequences and causes of plate motions. Geophysical Journal of the Royal Astronomical Society, 18(1), 1-32. https://doi.org/10.1111/j.1365-246X.1969.tb00259.x

Molnar, P., \& England, P. (1995). Temperatures in zones of steady-state underthrusting of young oceanic lithosphere. Earth and Planetary Science Letters, 131(1-2), 57-70. https://doi.org/10.1016/0012-821X(94)00253-U

Moresi, L., \& Gurnis, M. (1996). Constraints on the lateral strength of slabs from three-dimensional dynamic flow models. Earth and Planetary Science Letters, 138(1-4), 15-28. https://doi.org/10.1016/0012-821X(95)00221-W

Nichols, G. T., Wyllie, P. J., \& Stern, C. R. (1994). Subduction zone melting of pelagic sediments constrained by melting experiments. Nature, 371(6500), 785-788. https://doi.org/10.1038/371785a0

Peacock, S. M. (1990). Numerical simulation of metamorphic pressure-temperature-time paths and fluid production in subducting slabs. Tectonics, 9(5), 1197-1211. https://doi.org/10.1029/TC009i005p01197

Penniston-Dorland, S. C., Kohn, M. J., \& Manning, C. E. (2015). The global range of subduction zone thermal structures from exhumed blueschists and eclogites: Rocks are hotter than models. Earth and Planetary Science Letters, 428, 243-254. https://doi.org/10.1016/j. epsl.2015.07.031

Perrin, A., Goes, S., Prytulak, J., Davies, D. R., Wilson, C., \& Kramer, S. (2016). Reconciling mantle wedge thermal structure with arc lava thermobarometric determinations in oceanic subduction zones. Geochemistry, Geophysics, Geosystems, 17, 4105-4127. https://doi.org/ $10.1002 / 2016 \mathrm{GC} 006527$

Peterson, E. T., \& Seno, T. (1984). Factors affecting seismic moment release rates in subduction zones. Journal of Geophysical Research, 89(B12), 10,233-10,248. https://doi.org/10.1029/JB089iB12p10233

Plank, T., Cooper, L. B., \& Manning, C. E. (2009). Emerging geothermometers for estimating slab surface temperatures. Nature Geoscience, 2(9), 611-615. https://doi.org/10.1038/ngeo614

Poli, S., \& Schmidt, M. W. (2002). Petrology of subducted slabs. Annual Review of Earth and Planetary Sciences, 30(1), 207-235. https://doi. org/10.1146/annurev.earth.30.091201.140550

Rudnick, R. L. (1995). Making continental crust. Nature, 378(6557), 571. https://doi.org/10.1038/378571a0

Ruff, L., \& Kanamori, H. (1980). Seismicity and the subduction process. Physics of the Earth and Planetary Interiors, 23(3), 240-252. https:// doi.org/10.1016/0031-9201(80)90117-X

Rüpke, L. H., Morgan, J. P., Hort, M., \& Connolly, J. A. (2004). Serpentine and the subduction zone water cycle. Earth and Planetary Science Letters, 223(1-2), 17-34. https://doi.org/10.1016/j.epsl.2004.04.018

Ruscitto, D. M., Wallace, P. J., Cooper, L. B., \& Plank, T. (2012). Global variations in H2O/Ce: 2. Relationships to arc magma geochemistry and volatile fluxes. Geochemistry, Geophysics, Geosystems, 13, Q03025. https://doi.org/10.1029/2011GC003887

Savov, I. P., Ryan, J. G., D'Antonio, M., \& Fryer, P. (2007). Shallow slab fluid release across and along the Mariana arc-basin system: Insights from geochemistry of serpentinized peridotites from the Mariana fore arc. Journal of Geophysical Research, 112, B09205. https:// doi.org/10.1029/2006JB004749

Schmidt, M. W., \& Poli, S. (2014). Devolatilization during subduction. In R. L. Rudnick (Ed.), Treatise in geochemistry (2nd ed., Vol. 4, pp. 669-701). Amsterdam: Elsevier.

Skjerlie, K. P., \& Douce, A. E. P. (2002). The fluid-absent partial melting of a zoisite-bearing quartz eclogite from 10 to $32 \mathrm{GPa}$; implications for melting in thickened continental crust and for subduction-zone processes. Journal of Petrology, 43(2), 291-314. https://doi.org/ 10.1093/petrology/43.2.291

Syracuse, E. M., \& Abers, G. A. (2006). Global compilation of variations in slab depth beneath arc volcanoes and implications. Geochemistry, Geophysics, Geosystems, 7, Q05017. https://doi.org/10.1029/2005GC001045

Syracuse, E. M., van Keken, P. E., \& Abers, G. A. (2010). The global range of subduction zone thermal models. Physics of the Earth and Planetary Interiors, 183(1-2), 73-90. https://doi.org/10.1016/j.pepi.2010.02.004

Turcotte, D., \& Schubert, G. (2014). Geodynamics. New York: Cambridge University Press. https://doi.org/10.1017/CBO9780511843877

Turner, S. J., \& Langmuir, C. H. (2015). The global chemical systematics of arc front stratovolcanoes: Evaluating the role of crustal processes. Earth and Planetary Science Letters, 422, 182-193. https://doi.org/10.1016/j.epsl.2015.03.056

Ulmer, P., \& Trommsdorff, V. (1995). Serpentine stability to mantle depths and subduction-related magmatism. Science, 268(5212), 858-861. https://doi.org/10.1126/science.268.5212.858

van Hunen, J., van den Berg, A. P., \& Vlaar, N. J. (2004). Various mechanisms to induce present-day shallow flat subduction and implications for the younger Earth: A numerical parameter study. Physics of the Earth and Planetary Interiors, 146(1-2), 179-194. https://doi. org/10.1016/j.pepi.2003.07.027

van Keken, P. E., Hacker, B. R., Syracuse, E. M., \& Abers, G. A. (2011). Subduction factory: 4. Depth-dependent flux of $\mathrm{H}_{2} \mathrm{O}$ from subducting slabs worldwide. Journal of Geophysical Research, 116, B01401. https://doi.org/10.1029/2010JB007922

van Keken, P. E., Kiefer, B., \& Peacock, S. M. (2002). High-resolution models of subduction zones: Implications for mineral dehydration reactions and the transport of water into the deep mantle. Geochemistry, Geophysics, Geosystems, 3(10), 1056. https://doi.org/10.1029/ 2001GC000256

Wada, I., \& Wang, K. (2009). Common depth of slab-mantle decoupling: Reconciling diversity and uniformity of subduction zones. Geochemistry, Geophysics, Geosystems, 10, Q10009. https://doi.org/10.1029/2009GC002570

Wang, H., Agrusta, R., \& Hunen, J. (2015). Advantages of a conservative velocity interpolation (CVI) scheme for particle-in-cell methods with application in geodynamic modeling. Geochemistry, Geophysics, Geosystems, 16, 2015-2023. https://doi.org/10.1002/2015GC005824

Wiens, D. A., \& Gilbert, H. J. (1996). Effect of slab temperature on deep-earthquake aftershock productivity and magnitude-frequency relations. Nature, 384(6605), 153-156. https://doi.org/10.1038/384153a0

Zhong, S., Zuber, M. T., Moresi, L., \& Gurnis, M. (2000). Role of temperature-dependent viscosity and surface plates in spherical shell models of mantle convection. Journal of Geophysical Research, 105(B5), 11,063-11,082. https://doi.org/10.1029/2000JB900003 